\title{
Constructing of International Business Teaching Practice Mode Based on Professional Competence
}

\author{
L. YAN \\ Guilin Institute of Tourism, Guangxi, China
}

\begin{abstract}
With the emerging of market economic diversification, the demand for international business talent shows a variety of trends. International business courses need teaching practice innovation. The current teaching practice of vocational college should be built to competence-oriented teaching mode, innovated practical teaching methods, established progressive practice teaching modules, built a multi-level and threedimensional teaching system, and improved the teaching practice management and evaluation mechanisms. KEYWORD: professional competence; professional positions; teaching practice mode
\end{abstract}

\section{INTRODUCTION}

International Business is a high skillful and practical application profession. Its goal is to meet the requirements of globalization economic development, training operational ability to the whole process of international trade business and compound talents to achieve cross-regional, crosscultural management. However, the current international business education situation is not satisfied: On the one hand, schools focus attentions on a lot of resources, energy and money in the course of imparting knowledge and skills, the effect is not significant, on the other hand, more, high professionalism people are urgent for enterprises and society. To solve this problem, for schools it is particularly important tore model the students' cognitive ability, improve the professional skills and comprehensive capability. All of this, practical teaching is exactly essential part. So how to position accurately international business practice teaching, the urgency in teaching reform is that established realistic and reasonable practice teaching system.

\section{THE CURRENT QUESTIONS OF THE INTERNATIONAL BUSINESS PRACTICE TEACHING}

\subsection{Lacking of comprehensive practical courses design}

Nowadays, international business schools curriculum has been increased the amount of practical courses. On the one hand, this improvement is matched for vocational teaching objectives. On the other hand, it also reflects the professional skills requirement. But status quo is simply increasing the practical classes quantity, practical teaching still remains confirmation of theoretical courses, while ignoring the skillful demands. This teaching mode make the students are not interested in learning, but also ignore innovative ability.

\subsection{Not adequate for teaching practice resources}

Expenditure is used in construction of training base and simulation laboratory, which has especially bought computers and laboratory equipment. Research fund on practical teaching model, the experimental curriculum project and design are not enough. It will lead to the student is limited in the laboratory and the rooms for certain courses and simulation exercises, while ignoring the teaching system design integrity, teaching content, practice teaching methods still keep the old teaching mode, Which is long distance between teaching effects and expected results.

\subsection{Teaching practice system is incomplete, missing the monitoring mechanism of practical teaching}

Teaching practice system, including the teaching practice objectives, teaching content, methods and means of implementation, quality assurance mechanisms for teaching, teaching practice evaluation mechanisms and management. The various parts form a complete teaching practice system. The whole system in the process of 
implementation should focus on the integration. Currently, international business practice teaching System is mostly deficient in an effective quality assurance mechanism and quality evaluation mechanisms for practical teaching, such as poor practice teaching management mechanism, in perfect system, overlooking practice teaching management and low the integration of theorical teaching.

\subsection{Training of professional competence neglected}

Teaching practice teaching mode cannot be met the requirements of the students' practical skills, weakened innovative ability, the lack of awareness of the future career plans. Teaching activities either single-door practice course or integrated practice course, are not able to combine effectively classroom _teaching with future job skills, making it difficult to form the systematization knowledge and skills system required to vocational students. In conclusion, from the professional point of view, the current practical teaching modes lack on careeroriented. The curriculum is also too broad to achive integration and optimization of the course. Effective practice is to provide students the knowledge application channel for future career jobs, build practical teaching mode in line with the international business jobs and job skills.

\section{ANALYSIS OF OCCUPATIONAL ABILITY MATCHED INTERNATIONAL BUSINESS PROFESSIONAL JOB}

Occupational Ability refers to professional ability, practical ability and social skills that the related positions must possess. It means both theory and practical ability combination, including analysis, understanding and thinking, problem-solving skills as well as social responsibility, teamwork. It is divided into general professional competence and dedicated professional competence, The former means good work ethic and anti-compressing capability; resisting risks ability; cross-cultural communication skills; being good at computer and English, foreign trade software operational capabilities; good writing ability; independent thinking and the ability to work; Good love, dedication, hard-working ability; teamwork and communication skills; flexibility innovation ability, The latter is required vocational skills of different positions. In accordance with the appropriate level positions in international business, students should have different abilities. Such as junior positions are mastered knowledge of international trade regulations, foreign trade policy, capabilities of document full filing, knowledge of international finance and international settlement, international transport and insurance; middle positions are needed oral and written communication skills in foreign languages, prices calculation, chosen the trade terms correctly, high positions capabilities include financial management capacity, human resource management, strategic management, project management, international marketing management, risk management.

\section{BUILDING OF INTERNATIONAL BUSINESS TEACHING PRACTICE MODE BASED ON PROFESSIONALCOMPETENCE}

\subsection{Innovating the diverse experimental and practice teaching methods}

Traditional teaching means include role-playing approach, task learning, project-driven method, except for hand-made documents, case teaching ways, on-class discussion method. Curriculum system construction that international business talents training mode should be focused on workflow and business skills in all aspects. Because of the special nature of professional courses, training courses are usually arranged in the laboratory, completed in virtual environments.

\subsubsection{Project practice teaching approach on the platform —Simtrade simulation software}

Simtrade software is jointly developed by the Foreign Tradeniversity and Nanjing ShiGe software company. The students play different roles, for example importer \& exporter, to finish the whole the trade process on the Internet-based platform which stimulate real trading environment. Simtrade projets are divided into five stages according to workflow design. The first phase is project preparation: Teachers lead students to vist foreign trade enterprises, to know the appropriate workflow, and then guide the students are familiar with the software operating environment, the interface window, and other functions as soon as possible; The second phase is project implement: First of all, students are divided into several groups, two or three students form a group, play roles of importer, exporter. Students use their registered company to fulfil business independently. One person finishes 4-5 trades. Then the class is divided into 5-6 groups, playing different roles to race between teams. Finally, students will be ranked according to the final game score.

\subsubsection{Teaching practice mode on the platform of professional skills competition}

Participating in POCIB (Practice for Operational Competence International Business) competition is innovative mode of teaching practice. This competition is popular for recently years because of POCIB more accessible than Simtrade in platform 
interface, simulation software more operational, process design more innovative, more timely data updates. The students are set up in different country and carried out transaction with the others colleges from all over the country in internet environment. It is very fair that all students will finish transaction in E-mail on line. The rank is depended on team total scores. The students not only deeply understand the dilemma, mutual aid, solidarity and progress from competition, but also realize trade person's professionalism. Students have learned import and export price calculation, impact on product profit and financial condition, writing business letter as well as the documents filled out correctly, the significance of signing the contract \& performing contract.

\subsection{Establishing progressive teaching practice module}

Design of the practice teaching modules not only meet the requirements of teaching objectives, but also taking into account the students' vocational skills training. It is divided into cognitive training, professional skills training, comprehensive skills training (vocational qualification certificate training), social practical ability etc, which corresponding with cognitive practice module, skills practice modules, comprehensive practice module, social practice modules.

(1).Cognitive practice module has been concentrated on cognitive, observational skills trainings to cultivate professional cognitive ability, basic experimental skills, methods and means. (2).Professional skills training module has been carried out skills training to students according to professional characteristics. (3).Comprehensive practice module is mainly reflected the use of curriculum knowledge, especially the interoperability of skills courses, so that students possess the necessary professional competence. (4).Social practice modules have been improved the professional quality of the students' creative thinking and comprehensive practical ability.

\subsection{Constructing perfect multi-levels and Three- dimensional teaching practice system}

Multi-levels and three-dimensional teaching practice system may intergrate international business various courses knowledge, which the teaching goals are more clear and more purposeful. Practice teaching system is divided into three levels, three levels formed a school and practice teaching school teaching system. The first level is confirmation training and skills training on the basis of theorial courses and basic courses. Such as handmade documents, stimulating scene, analyzing cases are used basic skills practice, while course of theory and policy is used the theorial training. The second level integration of multiple comprehensive training courses, such as international trade comprehensive experiment has been intergrated many courses, like International Trade Practice, International Marketing, International Settlement. Entire knowledge chain is converted to the student's ability. The third level is school-enterprise cooperation mode that can improve the quality of students. There are order training mode and on-job practice mode. Three levels of teaching practice are combined closely with students career planning.

\subsection{Strengthening international business practice teaching management, evaluation and monitoring mechanisms}

Teachers are actors of teaching practice, and also the controller of the main teaching management activities. Which should be formed gradually the management team that consists of teachers and business elite, teachers constantly learn the latest information, management conception, practice skills to improve their practical guidance capability by entered enterprises occasional,. At the same time, enrich, review, develop teaching practice programs and practices guidebook, teaching practice summarize and refine the valuable information as development of the subject. Schools adopt to the teaching supervision system, formulate specific teaching methods by the relevant departments, and is responsible for the implementation of practical teaching plans, teaching process, practice base construction.

Teaching practice evaluation mechanisms includes two aspects, one is the assessment of learning outcomes for students, the other is teachers for practice teaching quality evaluation, it can be established in stages diversified evaluation mechanism. Teaching practice exams have been taken modular assessment ways for students, such as international marketing, business negotiations courses usually can be assessed scores with experiment lab showed\& experiment report \& final exam\& oral skills assessment module; international trade practice comprehensive experiments usually can be adopted experiment performance \& test report \& simulation software operation evaluation module. Students are encouraged to participate in the skills competition, while the skills competition results into practice teaching evaluation system, the overall quality of students have been increased rapidly. For teachers practice teaching quality assessment, can be set by the scientific relevant evaluation index. According to the process and results of practice teaching, it will be improved that practice teaching subjects and objects on practice teaching program implementation, and evaluation of 
the implementation of the effect, students' ability and other aspects.

\section{CONCLUSIONS}

International business teaching practice is a comprehensive system. The paper has combined professional competence with teaching goals, listed occupational ability matched professional job. It is drawn that constructing practice training and stimulation platform and skills competition modes in school, at the same time, emphasizing schoolenterprise cooperation and on-job practice mode out school. Textbook knowledge converts to the students' ability to adapt to meet the social requirement.

\section{ACKNOWLEDGEMENT}

This work was financially supported by the Project of Guangxi Higher Education Reform (2013JGB300).

\section{REFERENCES}

[1] DONGMEI LI. 2011.Practice Teaching System Construction based Innovative Competent. Friends of Accounting (1):57-59

[2] HONGLIANGYAN.2011.International logistics curriculum reform based on competence-oriented. Journal of Guangdong Communication Polytechnic(3): 45-48

[3] LIQUN TAN\&LINA DENG 2011. Research of innovative experimental teaching mode based on international business skills. Journal of Hebei University of Economic and Business (6):31-35

[4] LI YAN.2012. On Practice of International Trade Courses Teaching Based on Simtrade+POCIB. Journal of LIUZHOU Teachers College(5):100-102

[5] Phoebe Nilsen.2005. Practice Note: An International Dimension in Practice Teaching. International Review of Education. (5-6)

[6] R. Polancoet al.2004. Effects of a problem-based learning program on engineering students. Academic achievements in a Mexican university. Innovations in Education and Teaching International.

[7] WEIJIE LUO. 2009. Status and Inspiration of cooperation in running schools between Guangxi universities and ASEAN. Academic Forum(1):15-17

[8] XIAOYONG LI \&LITAO ZHOU.2010Research and Exploration on improving professional practice of computer. Computer Education.(1)

[9] YOU HUANG.2009.TeachingExploration on improving vocational colleges professional practices. Vocational Education Research.(12). 